\title{
Approaches to limit S-off-flavors during white wine fermentation with specific emphasis on yeast nitrogen nutrition
}

\author{
P. Wegmann-Herr ${ }^{\mathrm{a}}$, S. Ullrich, and D. Durner \\ Institute for Viticulture and Oenology, DLR Rheinpfalz, Breitenweg 71, 67435 Neustadt/W, Germany
}

\begin{abstract}
Low molecular weight volatile sulfur compounds are associated with the "reductive" off flavor of wines. The formation of 15 sulfide off-flavor compounds has been monitored with a novel HS-SPME GCPFPD method and SIDA quantification during white wine fermentation. Since it is known that glutathione (GSH) might buffer nitrogen stress of the yeast but can also lead to an increase of S-off-flavors, the effect of GSH addition was investigated. Fermentations were carried out in triplicate with Riesling musts showing low NOPA concentrations whereby we evaluated the effect of diammonium hydrogen phosphate (DAHP), pantothenic acid, inactive dry yeast based nutrient (IDY) and must oxidation. It could be shown that only the addition of $0.6 \mathrm{~g} / \mathrm{L}$ IDY increased fermentation speed and completed fermentations. The addition of IDY as well as GSH lead to a significant increase in $\mathrm{H}_{2} \mathrm{~S}$ formation. Total yeast cells were increased by must oxidation thus leading to faster fermentation whereby no significant difference in S-off-flavors could be observed. The addition of GSH did not affect yeast viability but increased significantly the negative effect of IDY addition regardless the S-off-flavor investigated. In all fermentations the use of DAHP reduced significantly S-off-flavor formation and could completely prevent both S-Methyl thioacetate and S-Ethyl thioacetate development. Under nitrogen deficient conditions, GSH can be used in white wine making when combined with DAHP.
\end{abstract}

\section{Introduction}

Low volatile sulfur compounds (VSC) have a large impact on wine quality. Some of the VSC's contribute actively to the varietal aroma of wines but most low molecular weight sulfur volatiles are considered to have a negative impact on wine aroma. Compounds like thiols, sulfides, disulfides and thioacetic acid esters are associated with the "reductive" off-flavor of wines. Their characteristic odors range from rotten egg, onion and garlic to cooked cabbage and rubber. The challenge in white wine making is to avoid S-off-flavors and at the same time negative effects of oxidation [1]. Yeast metabolism and yeast nitrogen nutrition are the major sources for S-off-flavor formation. One well described pathway to $\mathrm{H}_{2} \mathrm{~S}$ formation at low YAN concentrations is the sulfate reduction sequence pathway. But also organic peptides and S-containing amino acids can lead to a broad range of S-off-flavors [2]. The effect of glutathione addition and the effect of nitrogenmodification were investigated in regard to the formation of volatile sulfur compounds with Riesling-must showing low NOPA concentrations $(<90 \mathrm{mg} / \mathrm{L})$.

\section{Materials and methods}

\subsection{Experimental winemaking}

Monitoring the formation of volatile sulfur compounds and yeast viability, the analysis of the yeast assimilable nitrogen concentrations and the quantitation of glutathione concentrations during vinification were the main focuses of this study. In 2016 and 2017 fermentations were

a e-mail: pascal.wegmann-herr@dlr.rlp.de carried out in triplicate with sterile Riesling musts showing low NOPA concentrations whereby we, firstly, evaluated the effect of diammonium hydrogen phosphate at $1 \mathrm{~g} / \mathrm{L}$ (DAHP), pantothenic acid at $250 \mu \mathrm{g} / \mathrm{L}$ and one yeast autolysate based nutrient at $0.6 \mathrm{~g} / \mathrm{L}$ (IDY). In 2017 no pantothenic acid was used anymore but must oxidation was included into the experimental setup. All fermentations were carried out with addition of glutathione $(40 \mathrm{mg} / \mathrm{L}$ in 2016 and $50 \mathrm{mg} / \mathrm{L}$ in 2017) or without. The different parameters for both vintages are given in Table 1 .

\subsection{Analysis}

Fermentation control was performed with an oscillating U-tube density meter (DMA 35 Anton Paar). Total yeast population and yeast viability were determined by flow cytometry (CyFlow ${ }^{\circledR}$ Cube 6 at $\left.\lambda=488 \mathrm{~nm}\right)$. Sulfide offflavors were monitored by a recently published method [3], using solid phase microextraction followed by gas chromatography coupled with a pulsed flame photometric detector (HS-SPME-GC-PFPD). Furthermore, a stable isotope dilution assay (SIDA) without any mass-selective detection was applied for quantification using isotopic (deuterated) internal standard compounds synthesized inhouse. Separation between labelled and non-deuterated compounds could be realized with a $60 \mathrm{~m}$ fused silica column $(0.32 \mathrm{~mm}$ i.d.) coated with an apolar stationary phase of $100 \%$ dimethyl polysiloxane $(1 \mu \mathrm{m}$ film thickness), utilizing the inverse isotope effect [4]. The extraction step was carried out by using a $50 / 30 \mu \mathrm{m}$ DVB/CAR/PDMS fiber from Supelco® which was $2 \mathrm{~cm}$ in length. 
Table 1. Basic initial parameters of the must for the experimental setups.

\begin{tabular}{|c|c|c|c|}
\hline Vintage & Yeast & $\begin{array}{c}\text { Density } \\
{ }^{\circ} \mathbf{O e}\end{array}$ & $\begin{array}{c}\text { NOPA } \\
\text { mg/L }\end{array}$ \\
\hline 2016 & Oenoferm Riesling (Erbslöh) & 83 & 78 \\
\hline 2017 & Oenoferm bouquet (Erbslöh) & 85 & 59 \\
\hline
\end{tabular}

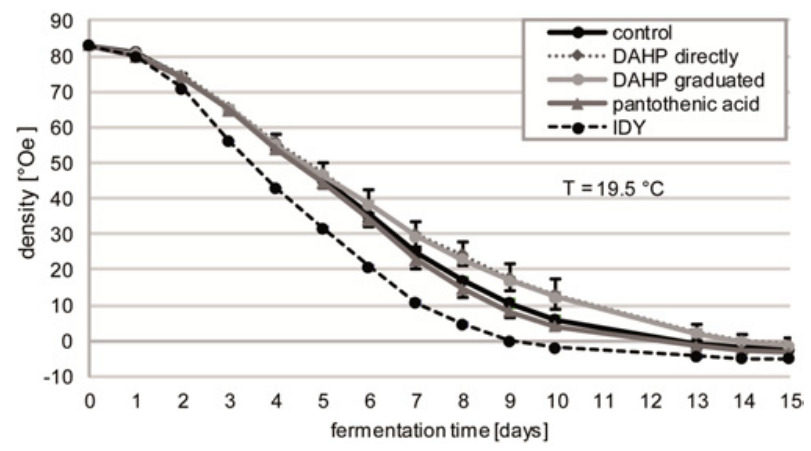

Figure 1. Fermentation dynamic at different nitrogen regimes $(n=3)$.

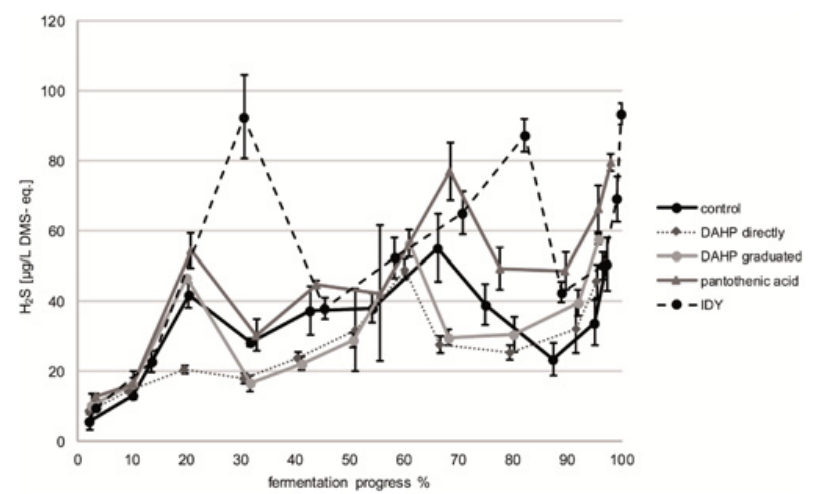

Figure 2. $\mathrm{H}_{2} \mathrm{~S}$ formation during the fermentation progress at different nitrogen regimes $(n=3)$.

\section{Results and discussion}

Regarding fermentation speed and degree of completed fermentation one can see that only the addition of $40 \mathrm{~g} / \mathrm{hL}$ IDY, containing organic nitrogen, could improve fermentation performance when using low NOPA containing Riesling must (Fig. 1). On the other hand the use of IDY lead to highest concentrations of $\mathrm{H}_{2} \mathrm{~S}$ and S-Methyl thioacetate when plotted against fermentation progress in \% (Figs. 2 and 3). Independent how the DAHP addition occurred the lowest $\mathrm{H}_{2} \mathrm{~S}$ formation and, compared to the other treatments, no S-Methyl thioacetate could be detected. In contrast to previous studies pantothenic acid did not show any positive effects. Independent of the S-off flavor investigated the addition of DAHP always showed the best effects. The timepoint of DAHP addition is not relevant in regard to prevent S-off flavor formation, therefore the addition of the total amount of $1 \mathrm{~g} / \mathrm{L}$ at the beginning of fermentation is to advice. For all fermentations the highest formation of $\mathrm{H}_{2} \mathrm{~S}$ is observed at about $20-30 \%$ fermentation progress and a further increase is at the end of fermentation (Fig. 2).

One reason for the increased hydrogen sulphide concentration due to the IDY addition (Fig. 2) might be the metabolism of GSH by the yeast. As already reported not

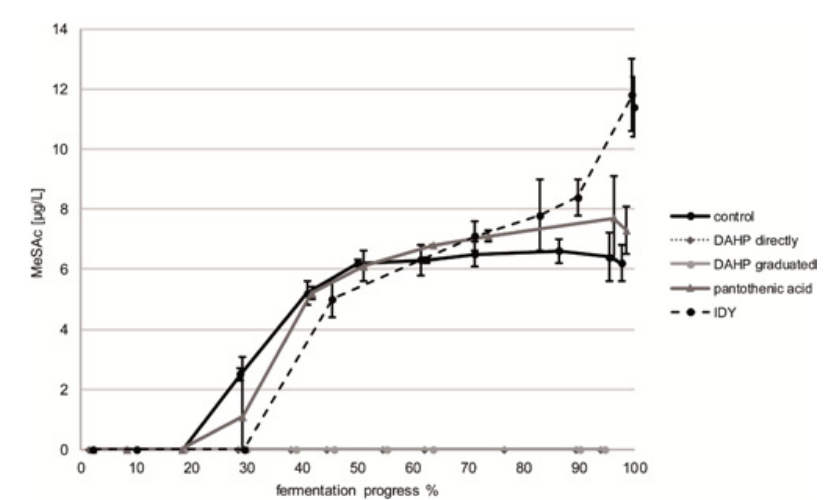

Figure 3. S-Methyl thioacetate formation during the fermentation progress at different nitrogen regimes $(n=3)$.

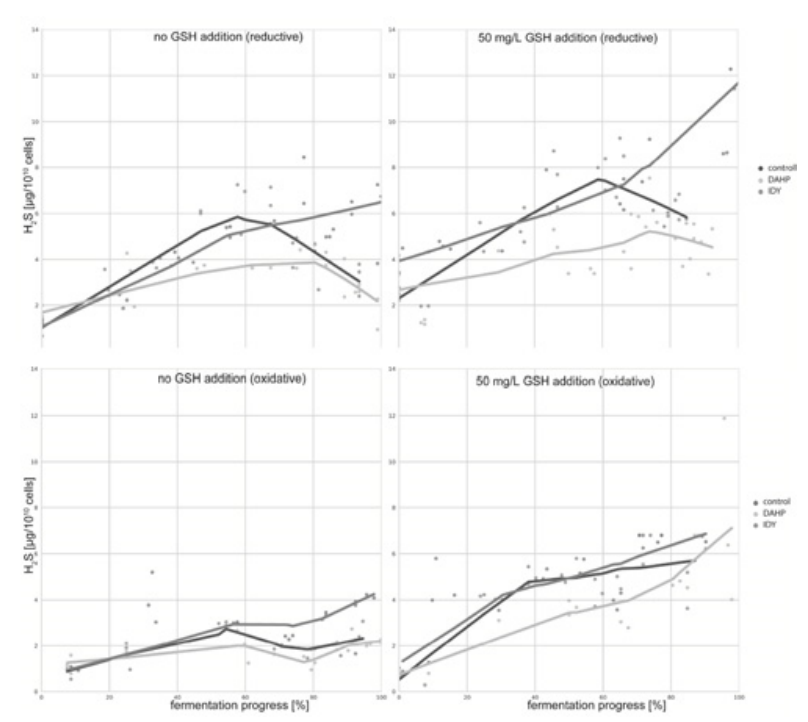

Figure 4. $\mathrm{H}_{2} \mathrm{~S}$ [ $\mu \mathrm{g}$ per $10^{10}$ cells] with and without GSH-addition (reductive must treatment above/oxidative must treatment below), LOWESS-regression $(n=3)$.

only the addition of GSH as pure substance but also in form of IDY can lead to the formation of S-off-flavors [5]. In the case of low yeast assimilable $\alpha$ - amino nitrogen the risk for the formation of $\mathrm{H}_{2} \mathrm{~S}$ is enhanced by the addition of GSH containing IDY even when compared to the control without any addition. Again we could show that under N-stress the yeasts metabolize the added $\mathrm{GSH}$ with subsequent $\mathrm{H}_{2} \mathrm{~S}$ production.

When adding $50 \mathrm{mg} / \mathrm{L} \mathrm{GSH}$ to must prior fermentation higher $\mathrm{H}_{2} \mathrm{~S}$ concentrations are detected independent of cell mass (Fig. 4). Plotting the $\mathrm{H}_{2} \mathrm{~S}$ concentration per $10^{10}$ cells versus fermentation progress in \% by LOWESSregression (locally weighted scatterplot smoothing) it becomes obvious that both reductive must treatment and IDY addition lead to the highest concentrations. Once again the positive effect of DAHP addition can be demonstrated, most likely due to the thereby reduced uptake of S-containing amino acids or GSH by the yeast. Even when in most of the cases the DAHP addition helps to prevent high S-off-flavor formation, high GSH supplementation is always a risk when low initial YAN levels are detected.

Generally lower $\mathrm{H}_{2} \mathrm{~S}$ formation can be observed when must oxidation was performed. This might be due to the observed higher yeast viability and therefore 
better fermentation performance or the already postulated quinone trapping. In this reaction $o$-quinones evolving from oxidized phenolic compounds react with mercaptans, which are responsible for sulphide off-flavors.

\section{Conclusion}

The wines with added diammonium phosphate yielded lower levels of volatile sulfur compounds and remarkably no S-methyl thioacetate or S-ethyl thioacetate were detected. The addition of glutathione did not increase the concentrations of volatile sulfur compounds when a sufficient nitrogen pool was provided, since the yeast was not forced to metabolise the added glutathione. Must oxidation led to a higher yeast viability and thus to faster fermentations. Furthermore, yeast viability was not affected by the addition of glutathione. All in all, glutathione combined with diammonium phosphate can be used safely during white wine fermentation if a nitrogen shortage is determined.
This work was supported by the Federal Ministry for Economic Affairs and Energy (via AiF) and the FEI (Forschungskreis der Ernährungsindustrie e.V., Bonn) Project AiF 18645 N.

Special thanks to Johanna Kost and Parissa Paydar for their help during the experiments.

\section{References}

[1] M. Ugliano, B. Fedrizzi, T. Siebert, B. Travis, F. Magno, G. Versini, P.A. Henschke, J. Agric. Food Chem. 57, 4948 (2009)

[2] J.H. Swiegers, I.S. Pretorius, Appl. Microbiol. Biotechnol. 74, 954 (2007)

[3] U. Sebastian, S.K. Neef, H.G. Schmarr, J. Sep. Sci. 41, 899 (2018)

[4] H.G. Schmarr, P. Slabizki, S. Münchtnich, C. Metzger, E. Gracia-Moreno. J. Chromatogr. A. 1270, 310 (2012)

[5] P. Wegmann-Herr, S. Ullrich, H.G. Schmarr, D. Durner, Bio Web Conf. 7, 02031 (2016) 